\title{
Fermentação, o emblema filosófico de Becher
}

\author{
A.M. Amorim da Costa ${ }^{a}$
}

\section{Introdução}

No ano mesmo da sua formatura em Filosofia pela Universidade de Coimbra, publicou Vicente Coelho da Silva Seabra e Telles (1764-1804) a sua Dissertação sobre a Fermentação em Geral, e suas Espécies, saida a lume na Real Impressão da Universidade e oferecida a seu cunhado, o senhor Jozé de Vasconcellos Parada e Soiza (1). Redigida em Maio de 1787 e impressa em Outubro do mesmo ano (ref. 2, pg. 397), esta Dissertação é o primeiro escrito em português em que se defende a decomposição da água "em gaz inflammável, e ar puro, ou oxyginio", de acordo com as teses que vinham sendo sustentadas pela escola de Lavoisier.

Por isso mesmo, e pelo significado de que se pode revestir esta obra daquele que um ano mais tarde, publicaria o primeiro volume dos Elementos de Chimica que com o segundo volume, publicado em 1790 (2), haveriam de constituir marco particularmente importante na história da ciência química em Portugal, não queremos deixar passar este segundo centenário daquela publicação sem uma referência especial.

Meses depois da publicação da Dissertação sobre a Fermentação em Geral, e suas Espécies, o Jornal Enciclopédico de Lisboa fazia a sua recensão nestes termos: "nesta Dissertação trata o Autor da Fermentação em geral, das suas três espécies mais notáveis, isto he, da vinhosa, ou espirituosa, da azeda, e da podre, dos productos, que dellas resultão, expondo as condiçðes para ellas necessárias, os fenómenos que se observam desde o princípio até ao fim". Em toda esta Dissertação nada achamos de novo, (e ousamos affirmar que he quasi huma mera traducção, ou resumo do que sobre o mesmo assumpto diz Mr. Fourcroy). Mas consistindo (segundo diz o Autor) o principal objecto da referida Dissertação, em explicar a verdadeira causa dos fenómenos da fermentação: causa que escapara a todos os químicos; e persuadindo-se ser o primeiro que a desenvolveo, e tirou da escuridade, em que estava, conclue, e decide que he a decomposição d'agua a benefício do calor; a qual decompondo-se em gaz inflammavel, e ar puro, ou oxyginio, "parte do qual se combina com o principio carbonáceo da matéria mucilaginoso-Sacharina, forma o ácido cretáceo, que sahe à superficie em forma de bolhas, e parte se combina com huma porção de óleo existente na matéria fermentante, e forma o ácido de tartaro: e que o gaz inflammável d'agua se une com outra porçẫo d'óleo da matéria Sacharina, $e$ dá o espírito de vinho". Mas como as experiências de Lavoisier, e Meunier sobre que se funda a decomposição d'agua nem são concludentes, nem ainda verificadas, antes por outras posteriores de Químicos excellentes têm sido desmentidas, parece-nos ser assás imaginá- ria a supposta causa dos fenómenos da fermentação, como também o são as conclusð̃es que della tira".

"Não podemos porém deixar de recomendar esta Obra pelas coizas interessantes, que contém, e sobre tudo pelas experiências, que trás acerca do Ether, feitas pelo Autor com muito cuidado, e tino; as quaes fazem esperar que poderá algum dia dar à luz composiçøes mais perfeitas, e vir a ser com o tempo, assídua applicação, e repetidas experiências um excellente quimico. Assim elle se esmerasse mais na adopção dos termos, e não introduzisse em tão pequena Obra tantos vocábulos bárbaros, como por exemplo, acides, acidificante, averdongada, lactescência, lactescente, mucosidade, putrefacção pútrida, retrogredir, robur, sicides, tartaroso, e outros muitos" (3).

Vicente Coelho de Seabra não frustaria a esperança expressa nesta recensão crítica. Nesse mesmo ano de 1788, como já o dissemos, publicaria ele o primeiro volume dos Elementos de Chimica de cujo conteúdo ressalta à saciedade ser ele "hum excellente quimico". Nesta sua obra, ao escrever sobre a composição da água, em longa nota complementar da notícia referente à confirmação da composição da mesma pelas experiências realizadas no Laboratório Chímico da Universidade de Coimbra pelos Doutores Vandelli, Sobral e outros, Seabra refuta as acusaçð̋es da recensão do Jornal Enciclopédico, referindo-se em pormenor às experiências de Monge, Lavoisier, Meusnier, Fourcroy, Priestley e La Mértherie, e sua interpretação dos resultados obtidos (ref. 2, pp. 204-208). Fazendo-o, ele declara expressamente que "a theoria stahliana moderna he sem fundamento"' (ref. 2, pg. 309), num repto directo à sem-razão da teoria do flogisto: "porque razão o phlogisto de Stahl há de entrar em tudo quanto há em chimica com as máscaras, que lhe quizermos dar? Porque não entrará somente, quando deve, a matéria do calor, luz ou fogo? Para quê romances, quando há factos? Para quê sonhar ou conjecturar, quando não he preciso?"' (ref. 2, pag. 208).

Pese embora esta dura crítica que tece ao sistema de Stahl, impðe-se reconhecer que a importância que Vicente Seabra dá ao problema da Fermentação em geral e suas espécies, tomando-o, inclusivé, para assunto do seu primeiro escrito químico, se insere numa linha estritamente stahliana. Stahl (1660-1734) definiu o seu sistema na sequência da filosofia quimica de Becher (1635-1682). E o próprio Vicente Seabra viria a escrever, em 1800, na sua Memória sobre os Prejuizos causados pelas Sepulturas dos Cadáveres nos Templos e Méthodos de os prevenir: "na fermentação se verifica o emblema filosófico de Becher circulos aeterni

\footnotetext{
a Dept. de Química - Univerdade - 3000 Coimbra
} 
motus", o círculo do movimento perpétuo (ref, 4, pg. 8). $\mathrm{Na}$ fermentação em geral (e em cada uma das suas três espécies, em particular, a espirituosa ou vinhosa, a àcida e a pôdre), se dá a decomposição das substâncias que a sofrem, tornando-se essa decomposição princípio de novas composiçðes. Do ponto de vista filosofico, como do ponto de vista químico, a fermentação é tida como o processo fundamental do crescimento e mudança de todas as esferas da natureza.

Por isso, Fourcroy, na sua Filosofia Química, se refere a ela nestes termos: "assim que os vegetaes e os animaes acabão de viver, os seus productos se tirão dos individuos a que pertencião, excitão-se nelles movimentos, que destroem sua tea, e alterão sua composição. Estes movimentos constituem as diversas espécies de fermentação. O fim da natureza em excitallos he claramente fazer mais simples os compostos formados pela vegetação e animalisação, e de os fazer entrar em novas combinaçð̃es de diversos géneros. IHe huma porção de matéria, que empregada por algum tempo na fábrica do corpo dos vegetaes e dos animaes, deve, depois de concluidas suas funçð̄es respectivas, servir para novas composiçð̋es" (ref. 5, Tit. XII, n.I, pp, 226-227). E reconhecendo a especial importância desta operação da natureza, reserva-lhe todo um longo capítulo da sua obra, em lugar separado e destacado daquele em que, em breves parágrafos, trata das demais operaçðes químicas da natureza: a calcinação, a fusão, a evaporação, a sublimação, a destilação, a dissolução, a precipitação, a infusão, a maceração, etc., etc. (ref. 5, Art. VI, pp. 35-46).

\section{Vitalismo, misticismo e química}

Com a Revolução Científica dos séculos XV-XVII, a imagem que o homem se fazia do mundo foi inevitavelmente substituída, pouco a pouco, pela imagem de um mundo identificado com uma grande máquina. Foi o triunfo do chamado mecanicismo. As filosofias antigas que consideravam o mundo como um vasto organismo vivo foram relegadas para segundo plano. Não desapareceram, porém; muito pelo contrário, algumas das correntes que então assumiram tiveram grande impacto no mundo da nova ciência. É o caso, por exemplo, das filosofias neo-platónicas, de M. Ficino (1433-1499), I1. Cornelio Agrippa (c. 1486-1535) e J. Baptista Porta (c. 1535-1615) que consagravam a divisão tripartida e hierárquica do cosmos em corpo, alma e espirito, as três componentes de um organismo vivo. A matéria seria meramente passiva; na natureza, a alma do mundo seria a fonte imanente de toda a actividade; e o espírito seria o veículo intermediário para a transmissão do poder da alma à matéria. É, ainda, o caso do naturalismo das filosofias de $B$. Telésio (1508-1588), T. Campanella (1568-1639) e G. Bruno (1548-1600) em que a estrutura tripartida do cosmos é reduzida a dois termos últimos, a matéria e uma entidade activa que tudo impregna, correspondente a uma unidade resultante da alma mais espírito das filosofias anteriores. E é, sobretudo, o caso do vitalismo desenvolvido por Paracelso (1493-1541), J.B. Van-I Helmont (1577-1644), Stahl (1660-1734) e Leibnitz (1646-1716). Paracelso, ao professar a constituição do cosmos a partir dos quatro elementos de Empédocles e Aristóteles, terra, ar, água e fogo, professava também que cada um destes elementos era constituido por três princípios, o enxôfre, o mercúrio e o sal, vivificados por un archeus, sôpro divino emanado do sistema solar, de tal modo que a esses elementos assentaria melhor o qualificativo de almas de preferência ao qualificativo de matéria.

Van-Helmont transformaria os elementos de Paracelso numa pluralidade de sementes de matéria, ou semina, entidades vivas cuja acção transformadora seria determinada pelo archaeus que as informava.

É, sobretudo, dentro deste vitalismo filosófico de origem paracelsiana, que o fenómeno da fermentação assume particular interesse na explicação dos fenómenos químicos, nos séculos XVII e XVIII. E já no século XIX, ficaria famosa a controvérsia entre a natureza da fermentação alcob́lica, cada qual sustentando, até morrer, interpretaçōes diferentes (6). As posiçס̄es em confronto nesta controvérsia radicam-se numa posição vitalista, por parte de Pasteur, contra uma posição anti-vitalista, por parte de Liebig (7).

Para os vitalistas, nada no universo pode ser considerado totalmente morto e, consequentemente, totalmente incapaz de vida (8). A fermentação em geral, e nas suas várias espécies, é disso manifestação. Não surpreende, pois, a definição que N. Lemery (1645-1715), no seu Curso de Química nos dá deste fenómeno: "a fermentação é uma ebulição causada por espíritos que procuram sair do corpo em que se encontram, ao encontrarem partes terrestres e grosseiras que se opð̄em à sua passagem fazem inchar e rarificar a matéria até que se consigam desprender; neste desprendimento, os espíritos dividem, subtilizam e separam os princípios, transformando a matéria em natureza diferente do que era antes"' (ref. 9, pp. 34-35).

O próprio Lemery contrapunha a esta definição a possibilidade de definir mais exactamente a fermentação como sendo um "movimento intestino que se excita naturalmente em certos corpos líquidos, ou pelo menos húmidos, pelo qual os princípios constitutivos destes corpos agem uns sobre os outros"' (ref. 9, pg. 34, nota e).

Esta ideia de "um movimento intestino" que se excita naturalmente, isto é, por si-próprio, seria a consagrada no Dicionário de Química de Macquer (ref. 10a, pp. 493-484); 10b, pg. 159) e foi aceite pelos mais consagrados autores químicos que aceitando-a, procuraram, pouco a pouco, identificar a causa de um tal movimento.

A Dissertação sobre a Fermentação em Geral, e suas Espécies e, depois, os Elementos de Chimica de Vicente Seabra, fazem outro tanto: "todas as partes fluidas, molles, e algumas sólidas (exceptuando muito poucas) dos reinos organisados e expostos ao ar, e a hum certo gráo de calor, põe-se em hum movimento intestino mais, ou menos sensível, segundo a sua natureza, e gráo de fluidez; e depois disto mudão de natureza, e propriedades. Esta alteração chama-se em geral Fermentação, e he devida principalmente à decomposição d'agoa'.

\section{A doutrina vitalista de Stahl}

Ao considerar a influência do vitalismo na explicação dos fenómenos químicos, nos alvores da nova ciência saída da Revolução Científica dos séculos XV-XVII, impōe-se realçar o chamado sistema de Stahl, pela verosimilhança com que se afirmou, estribado em sólidos, experimentaes e racionaes fundamentos, como dele haveria de dizer J. Rodrigues d'Abreu (1682-1752) (ref. 11, Livr. I, pg. 1), "o introdutor de Stahl no nosso país" (12). Martinho de Mendonça (1693-1743), no 
Proémio à Historologia Médica deste insigne Médico não hesitou em denominar esse sistema de sistema Animástico por se tratar de um sistema que admite - para usar as próprias palavras de Martinho de Mendonça - "humas substâncias Immateriaes, Activas ou Moventes em que se recebe a Vida" (ref. 11, Proemio). W Rodrigues d'Abreu, ao longo de toda a obra em referência, repetidamente defende como doutrina de Stahl, que todos os Corpos Naturais são dotados de um espírito Vital, ou Princípio Activo Imaterial. Tudo é constituido por Terra Subtil mais ou menos disposta para a salsugem, de Óleo e de Água, a cuja união e separação preside aquele Princípio Activo que tem no movimento o seu instrumento principal.

E este Princípio Activo tudo obra pela proporção ou improporção dos movimentos internos e externos, onde a vida se conserva por um movimento contínuo e perpétuo. A fermentação em geral, e nas suas espécies, é um movimento natural integrado no movimento geral da via. Como diria Thomas Willis (1621-1675), "o homem não só nasce, e se nutre por benefício dos fermentos, como também morre devido a eles" e "os primeiros Princípios da Vida trazem a sua origem do espirito que existe no coração como ponto fermentante", (13). A mentalidade alquimista continuava bem viva, com a convicção profunda de ser possível a transformação radical dos metais vis em metais nobres, e a transformação radical do homem mortal em ser imortal, graças a acção desse 'fermento' misterioso por todos almejado, a Pedra Filosofal.

Todo este sistema Animástico de Stahl, particularmente no seu conteúdo químico, tem suas raizes na Physica Subterrânea de Becher (14), e insere-se na corrente dominante da filosofia química do século XVII dos iatroquímicos, professos discípulos de Paracelso e Van-IHelmont. Caracteriza-o uma certa rejeição da filosofia mecanicista e seu apelo ao tratamento matemático do conhecimento da Natureza, com redobrada profissão de fé na mais pura das crenças vitalistas.

Sob o ponto de vista químico, o sistema Animástico de Stahl é mais conhecido por sistema flogista, por tomar para base da constituição química de todos os corpos, a Terra Subtil, a terra pinguis da Física de Becher, identificada, na sequência duma tradição relativamente longa e antiga, com o principio alquimista enxôfre, já por outros, mais que uma vez, designado por flogisto para salientar o seu carácter inflamável (ref. 15, pp. 461 ss.)

Como o foi para Becher, também para Stahl e seus sequazes, a fermentação é tema fundamental na explicação de todos os fenómenos químicos. O simples título do tratado que expressamente escreveu sobre o assunto nos dá conta disso: Zymotechnia fundamentalis, seu fermentationis theoria generalis, qua nobilissimae hujus artis, et partis chymiae, utilissimae atque subtilissimae, causae et effectus in genere, ex ipsis Mechanico - Physicis principiis, summo studio eruuntur, simulque experimentum novum sulphur rerum arte producendi, et alia utilia experimenta atque observata, inseruntur (16).

Em Portugal, antes do já mencionado tratado de Rodrigues d'Abreu, a Farmacopea Lusitana de D. Caetano de Santo António, nas suas diversas ediçōes (17), ignora por completo a orientação química de Becher e Stahl, e as únicas operaçoes químicas a que faz referência são a cozedura, a lavagem, a infusão e a trituração. Outro tanto não acontece, porém, com o Thesouro Apollíneo, Galénico, Chímico, Cirúrgico e Pharma- cêutico (1714) ou com a Pharmacopea Ulyssiponense (1716) de Joam Vigier (18-19). Embora "mais catálogo de remédios do que especulação de causas; mais compêndio de mezinhas, do que ponderação de texto", como o autor se apressa a dizer no seu Prólogo ao Leitor, o Thesouro Apollíneo aparece realmente informado por uma "racionaçam da Escola Moderna sobre as causas efficientes", como se lê no seu longo subtítulo, de inspiração paracelsiana, quando depois de definir os medicamentos como "tudo o que pode alterar a natureza", afirma tratar-se de "compostos de cinco princípios, huns activos, outros passivos. Os activos são o mercúrio ou espírito, o enxôfre ou b́leo, e o sal; os passivos, a fleima ou água, e a terra ou caput mortuum" (ref. 18a, pp. 1-2). E logo a seguir, precisa que o enxôfre ou óleo é "tudo o que facilmente se inflama e arde"' (ref. 18a, pg. 2).

E fala da fermentação como uma das operaçðes que servem para acrescentar a virtude dos medicamentos, fim a que servem também a destilação, a calcinação e a detonação (ref. 18a, pg. 4), enquanto a lavação, infusão, evaporação, torrefacção, cristalização, etc... servem apenas para "corrigir alguma qualidade roim" dos mesmos (ref. 18a, pp. 4-9). E, em estilo tipicamente escolástico de pergunta e resposta, decreve-a nestes termos: "he hum movimento interior das partes de um mixto: por este modo se tirão muytos espíritos ardentes e muytos saes voláteis de algumas plantas infundidas em licor sufficiente por certo espaço de dias e para facilitar a fermentação se lhe pode ajuntar fermento de cerveja, ou hydromel, etc." (ref. 18a, pg. 5); ou ainda: "fermentação he uma ebulição ou fervura causada por partes voláteis para se desembaraçar das partes grosseiras, com as quaes se acham unidas" (ref. 18a, pg. 14). $\mathrm{Na}$ Pharmacopea Ulyssiponense, Joam Viger adopta a mesma definição de Fermentação e assinala-lhe a mesma finalidade - acrescentar a virtude dos medicamentos (ref. 19 , pg. 18 e pg. 56). Nada nos diz, porém, sobre a composição intrínseca dos medicamentos; considera apenas que se trata de compostos que produzem alteração em nossos humores quando tomados por dentro, ou aplicados por fora e limita-se a consideraçðes sobre o como obrão as diferentes espécies dos mesmos (ref. 19, pp. 2-3).

Anos antes da publicação da Historologia Médica de Rodrigues d'Abreu e também alguns anos antes do aparecimento das Farmacopeias que acabamos de referir, Curvo de Semmedo (1635-1719) na sua Polyanthea Medicinal, em 1697, (20), mostrava-se bem mais actualizado relativamente às correntes iatroquímicas de então; e expressamente refere e professa a teoria dos tria prima (enxôfre, mercúrio e sal) de Paracelso e Van-Helmont, nomes que repetidamente cita com reverência e admiração: "qualquer corpo terrestre consta destes três princípios" (ref. 20c, pp. 718-719). E da fermentação diz tratar-se de "hum movimento particular que se exalta nas entranhas ou partes interiores de todas as cousas sublunares, quando intentão passar a mayor perfeyção, ou transmutar-se para outro estado" pois "todas as acçoens pelas quaes se formão, se aperfeyçoão, se permutão e se destroem os corpos, são governadas da fermentação (...); o enfermarem, ou conservarem-se os homens sãos, depende da boa, ou ma fermentação"' (ref. 20c, pg. 715).

Estritamente afecto à tradição de Becher e Stahl se revela Manoel Henriques de Paiva (1752-1829) naquela que a si mesma se apresenta como "a primeira obra chimica que em nossa linguagem sahe a luz", os seus 
Elementos de Chimica e Farmácia (21), já quando Lavoisier movia cerrada guerra às doutrinas flogistas. Seguindo de perto, em particular, Boerhaave e Scopoli, nesta sua obra, Henriques de Paiva defende que os principios activos que penetram a composição intima de todos os corpos são o Fogo, o $A r$, a Água, os Saes, e os Corpos Flogísticos (ref. 21, pg. 13). A fermentação dos corpos é apresentada como uma consequência imediata do Fogo e do $\mathrm{Ar}$ que os compōe, à semelhança do que acontece também com a Putrefacção e a Fatiscência (ref. 21 , pp. 26-27). Ora espontânea, ora excitada, ela é um movimento intestino devido ao calor que nasce do fogo inospitante do corpo em que ocorre que aquecendo-o, faz desprender parte do ar nele existente, e juntamente alguma parte do seu princípio inflamável (ref. 21, pg. 26 e pg. 32). Desse movimento nascem produtos que antes não existiam na substância fermentante. É em razão dos produtos que se podem formar que Itenriques de Paiva considera as três diferentes espécies de fermentação, a vinhosa, a espirituosa e a ácida em que se obtêm, respectivamente, vinho, espírito ou vinagre.

Apoiando-se em experiências realizadas por Sage, Rome de l'Isle e outros, Inenriques de Paiva nota, precisando uma afirmação de Scopoli, que o fluído aeriforme que se desenvolve na Fermentação e se detem sobre o suco fermentante "he inteiramente distinto do ar", identificando-o com o "ácido marinho volátil", "gaz mefytico", "acido cretáceo ou aéreo"' (ref. 21, pg. 30). A Dissertação sobre a Fermentação em Geral e suas Espécies de Vicente Seabra está marcada por toda a motivação de inspiração vitalista, em que a maioria dos químicos de então se apoiava para fazer do tema, assunto de particular realce nos seus tratados. Deles se demarca, porém, na explicação que procura para tão importante fenómeno químico.

Como já acima referimos, para Vicente Seabra a Fermentação em Geral é um movimento intestino que ocorre em todas as partes fluidas e moles dos reinos organizados, quando expostas ao ar e a um certo grau de calor. Sob a sua acção, as substâncias que a sofrem mudam de natureza e propriedades. Para que ocorra, são precisas, pelo menos, as três condiçð̄es seguintes: "1. Hum certo grao de fluidez - os corpos secos não fermentam;

"2. Hum certo grao de calor diverso nas diversas fermentaçð̄es. O frio oppōe-se a todas;

"3. O contacto do ar. Os corpos no vácuo não se alteram".

As matérias gomoso-sacarinas são as únicas em que se verifica a fermentação espirituosa. A decomposição da água pelas matérias combustíveis destas substâncias a benefício do calor é a causa do movimento intestino observado. Nela, o oxigénio da água combinar-se-ia parte com o princípio carbonáceo para formar o ácido carbonáceo que subindo à superfície do líquido fermentante é a causa das bolhas que se observam, e parte combinar-se-ia com uma porção do óleo existente no corpo fermentante para formar o ácido tartaroso. Por sua vez, o hidrogénio resultante da mesma decomposição da água, unir-se-ia com a outra porção de óleo existente no corpo fermentante, porventura a mais subtil, formando o chamado espírito de vinho. O contacto com o ar é preciso, tanto para que com o seu peso favoreça a desenvolução dos gases, decomposição da água, e combinação dos seus princípios, como ainda para fornecer algum oxigénio preciso. A nimia fluidez, afraca a acção dos princípios referidos, enquanto que uma fluidez muito espessa não deixa que os mesmos princípios obrem livremente e com energia uns sobre os outros, donde resulta uma fermentação imperfeita. Logo, para que os princípios referidos obrem com energia, e se tenha uma boa fermentação espirituosa, o líquido fermentante deve ser nem muio fluido, nem muio espesso.

A fermentação ácida ocorre nas gomas, no amido ou fécula, nos vinhos, principalmente quando não separados da borra, e, em geral, nas substâncias viscoso-ácido-fluidas, quando expostas ao ar e a uma temperatura entre os $20-25^{\circ} \mathrm{C}$. A sua causa é também a decomposição da água a benefício do calor, em que parte do oxigénio se combina com a parte oleosa do espírito de vinho, e forma o vinagre, enquanto que a restante parte acaba de saturar o ácido tartaroso e o torna também em vinagre, ou se combina com o princípio carbonáceo e forma o ácido carbonáceo que se desenvolve.

Por sua vez, a fermentação pôdre observa-se em todas as substâncias vegetais e algumas animais, depois de sofrerem a fermentação ácida, principalmente se se não separaram do seu sedimento. A maior parte das espécies animais padece somente este tipo de fermentação ou, pelo menos, passam insensivelmente pelos outros. A decomposição da água é ainda a sua causa, tal como nos dois tipos anteriores: nela, parte do oxigénio resultante dessa decomposiçâo combina-se com o princípio carbonáceo, e forma o ácido carbonáceo que se desenvolve; a outra parte combina-se com uma porção de mofeta, e forma o ácido nítrico, que unindo-se à base alcalina forma os sais nitrosos, que se acham nos lugares onde apodrecem estas matérias. O hidrogénio proveniente da mesma decomposição da água combina-se em parte com outra porção de mofeta e origina o amoníaco, ou se une com o calor e forma o gás hidrogénio que se desenvolve. À medida que se desenvolve esta decomposição, o corpo seca-se, torna-se mais ou menos denegrido, friável e polverulento até se transformar por completo em terra vegetal ou animal.

$\mathrm{O}$ progresso de qualquer das três espécies de fermentação pode ser retardado de três modos: (i) expondo o corpo fermentante a uma temperatura muito fria. O frio condensa a água e a matéria fermentante e, por consequência, inviabiliza a decomposição das mesmas; (ii) proibindo o acesso do ar, e não deixando vazio algum no vaso em que se contém a matéria fermentante. Assim se impede o desenvolvimento das matérias gasosas necessárias ao movimento intestino fermentativo; (iii) impedindo-se directamente e decomposição da água, o que é possível por recurso aos chamados adstringentes, e em geral aos corroborantes que diminuem a afinidades da água com os princípios do corpo fermentante, ou então, privando o corpo de toda a humidade.

Fiel a esta sua visão da fermentação em geral, e suas espécies, Vicente Seabra, como censor da Faculdade de Filosofia da Universidade de Coimbra, não aprovou a um conclusionista a tese dada pelo mesmo em Botânica, sob orientação do Professor Avelar Brotero, onde se defendia que toda a germinação é autêntica fermentação: "omnis germinatio vera est fermentatio". A atitude de Vicente Seabra foi motivo de acesa desavença com o referido Professor Avelar Brotero, como textualmente o declara o mesmo Vicente Seabra na sua já referida Memória sobre os prejuízos das Sepulturas nos Templos (ref. 4) e numa carta que dirigiu ao Ministro de Estado D. Rodrigo de Sousa Coutinho (22). Na primeira se lê, em nota de roda-pé, a propósito das 
três espécies de fermentação: "em todas três há resolução, e decomposição daquellas substâncias, e outras novas composiçðes. Daqui se vê o grande engano, em que estão alguns Botânicos, quando affirmão, que na germinação das sementes há huma fermentação; e apezar de que esta proposição seja abraçada como huma verdade philosophica, e ensinada aos discípulos pelo actual Lente de Botânica da Universidade de Coimbra, o Dr. Teles de Avellar Brotero, com tudo sem offender ao conceito que este Professor merece em Botânica pura, não se pode tolerar semelhante proposição à vista dos actuaes conhecimentos chimicos, e phisiológicos. Pela germinação se desenvolvem, e se formão os vegetaes pela recepção, disposição e apposição proporcionada dos sucos nutritivos, que a nova planta recebe dos cotylidðes pelos vasos umbilicaes, bem como os animaes recebem da placenta; e pela fermentação se resolvem, e se decompøem os corpos tanto vegetaes como animaes. Esta verdade basta para que se conheça a falsidade daquella proposição (ref. 4, pg. 8).

Pela carta de Vicente Seabra ao Ministro de Estado Sousa Coutinho se compreende melhor o ponto da situação a que chegara a dissenção entre os dois Professores, a que se reporta a nota que acabámos de citar. A desavença era clara e grave: "V. Ex. " quando lesse a Memória sobre os Prejuizos das Sepulturas nos Templos com rasão deveria notar o ter eu personalizado o Dr. Brotero em huma nota. Eu devo porém dizer a V. Ex. ${ }^{a}$ para m.a resalva, que aquelle lente pública e escandalosamente tem offendido a mim, e aos meus collegas: e porq. eu como censor da Faculdade não quiz approvar a hum de seus descipulos, digo, a hum conclusionista a seguinte these dada por elle em Botânica: ornnis germinatio vera est fermentatio - disse blasfémias contra mim, pois que para crédito meu devo procurar a minha desforra naquellas matérias mesmas, e únicas, em q. elle se julga protótypo; e se acaso elle (o q. talvez não fará) der à luz os seus compêndios de Agricultura, de q. está incumbido há 10 annos, eu tomarei o trabalho de medir então em campo raso a minha eșpada com a delle, e o público decidirá esta contenda que tão anciosamente quero emprehender" (22). Ocupando-se da germinação, Brotero dizia: "A germinação (germinatio), parece começar na fermentação própria para pôr em acto ou despertar, pelo assim dizer, o princípio vital potencial, que se acha no corculo da semente. A humidade penetrando pelas suturas da casca (se as há), e pelo embigo da semente, ajudada do calor competente estabelece hum movimento intestino nas cotyledones, e na plântula seminal, amollece-as pouco a pouco, e dá princípio à vegetação; amollecidas e inchadas sufficientemente as cotyledones, rebentão os tugumentos, e a radícula e plúmula começão a engrossar e prolongar-se, nutridas pelos succos lácteos, que lhes são transmittidos pelas cotyledones; huma dirige-se para baxo a fim de formar a raiz, e a outra destinada a ser tronco cresce para cima e surde da terra, pondo fim ao periodo da germinação seminal" (ref. 23, Tom. I, pp. 233-234).

Para Vicente Seabra, os cotiledones seriam apenas armazéns dos sucos nutritivos. Estes, na altura da germinação, passariam, sem sofrer qualquer alteração, para os vasos que os conduziriam para os diversos pontos do rebento que, pela sua recepção, disposição e aposição se começariam a desenvolver. Enquanto que para Brotero, na germinação as substâncias contidas nas sementes sofriam uma decomposição molecular, para Vicente Seabra tal não tinha lugar. No processo verificar- -se-ia apenas desenvolvimento e nehuma decomposição pelo que, no seu conjunto, não poderia nunca ser considerado como fermentação (25).

De acordo com o estado da ciência da época, a posição dos dois cientistas mais não poderia ser que uma posição de pre-ciência e expectativa cientifica (24). Todavia, este incidente entre os dois distintos Professores da então Faculdade de Filosofia da Universidade de Coimbra, mostra-nos bem quanto ao findar do século XVIII havia ainda de pouco claro na interpretação da natureza do fenómeno da fermentação e da sua real extensão no domínio dos fenómenos naturais. Como referimos já, essa interpretação continuaria controversa até aos tempos de Pasteur e Liebig. O facto, porém, de em 1787, Vicente Seabra se ter debruçado extensa e exclusivamente sobre o assunto, em termos de uma explicação nova, fundamentada em princípios básicos da nova quimica, a química pneumática da escola de Lavoisier, e com eles em inteira coerência, é precioso indicador do esclarecimento que assistia este químico português, cujos méritos da obra que produziu são dignos de todo o nosso reconhecimento. A sua Dissertação sobre a Fermentação em Geral, e suas Espécies foi o princípio dessa obra meritória. Sobre ele, duzentos anos são passados. Por sobre o tempo que constitui estes dois séculos, aqui ficam estas notas, em singelo preito que a seu mérito é devido.

\section{REFERENCIAS}

(1) Vicente Coelho da Silva Seabra e Telles, Dissertação sobre a Fermentação em Geral, e suas Espécies, Coimbra, Real Impressão da Universidade, 1787.

(2) Id., Elementos de Chimica, Coimbra, Real Officina da Universidade, Part. I, 1788; Part. II, 1790.

(3) Jornal Enciclopédico, Lisboa, Junho, 1788, pp. 244-245.

(4) Vicente Coelho da Silva Seabra Telles, Memória sobre os Prejuizos causados pelas Sepulturas dos Cadáveres nos Templos, e Méthodo de os Prevenir, Lisboa, Officina da Casa Litterária do Arco do Cego, 1800.

(5) A.F. Fourcroy, Filosofia Química ou Verdades Fundamentaes da Química Moderna destinadas a servir de Elementos no Estudo desta Sciência, Rio de Janeiro, Impressão Régia, 2. ${ }^{a}$ Ed., 1816 (Trad. Manoel Henriques de Paiva).

(6) Caberia a Büchner dirimir o fundamental desta controvérsia, com a descoberta acidental do agente causador da fermentação alcoólica. Cf. E. Büchner, Ber., 30, 117 (1897).

(7) H. Finegold, J. Chem. Educ., 31, 403 (1954).

(8) Francis Mercury van-Helmont, Two Hundred Queries moderately propounded concerning the doctrine of the Revolution of Humane Souls and its Conformity to the Truths of Christianity, Londres, 1684, pg. 106.

(9) N. Lemery, Cours de Chimie, Paris, Chez Laurent Charles d'Houry, 1757.

(10) (a) P.J. Macquer, Dictionnaire de Chymie, Paris, Chez Lacombe, 1769; (b) idem, Suiça, Chez Lib. Associés, 1779.

(11) José Rodrigues d'Abreu, Historologia Médica, Lisboa Occidental, Officina da Música, 1733.

(12) Luis de Pina, Dicionário da História de Portugal, Lisboa, Ed. Joel Serrão, col. III, pp. 3-8.

(13) Thomas Willis, Diatribe duae: de fermentatione, sive de motu intestino particularum in quovis corpore, 1659 , citado in ref. 11 , pp. 105 e 108 . Sobre esta obra de T. Willis ver, v.g., ref. 15 , pp. 520ss, 
(14) J.J. Becher, Physica Subterranea, 1669. Sobre esta obra de Becher ver, v.g., ref. 15, pp. 459ss.

(15) A.G. Debus, The chemical Philosophy, Nova Iorque, Science History Publications, 1977.

(16) G.E. Stahl, Zymotechnia fundamentalis, seu fermentationis theoria generalis, qua nobilissima hujus artis, et partis chymiae, utilissimae atque subtilissimae, causae et effectus in genere, ex ipsis experimentum novus sulphur verum studio eruuntur, simulque experimentum novum sulphur verum arte producendi, et alia utilia experimenta atque observata, inseruntur, Halle, Christop. Salfeld, 1697. Nota: Como se depreende do próprio título desta obra, Zimotecnia ou Zimogenia (do grego: $\zeta U ́$ $\mu \eta=$ fermento $+\gamma \epsilon \nu \nu \alpha \omega=$ engendrar) mais não é que a técnica de excitar e dirigir a fermentação. (17) D. Caetano de Santo António, (a) Pharmacopea Lusitana, Coimbra, Impressão de Joam Antunes, 1704; (b) idem, Lisboa, Real Mosteiro de São Vicente de Fora, 1711; (c) idem, Lisboa, Officina de Francisco Xavier de Andrade, 1725.

(18) Joam Vigier, (a) Thesouro Apollíneo, Galénico, Chímico, Chirúrgico, Pharmacêutico ou Compêndio de Remédio, Lisboa, Officina Real Deslandesiana, 1714; (b) idem, Coimbra, Officina de Luis Seco Ferreyra, 1745.

(19) Joam Vigier, Pharmacopea Ulyssiponense, Lisboa, Officina de Pascoal da Sylva, 1716.
(20) J. Curvo de Semmedo, (a) Polyanthea Medicinal, Notícias Gelénicas e Químicas, Lisboa, Officina de Miguel Deslandes, 1697; (b) idem, Lisboa, Officina Valentim da Costa Deslandes, 1706; (c), idem, Lisboa, Officina António Pedroza Galram, 1716.

(21) Manuel Joaquim Henriques de Paiva, Elementos de Chimica e Farmácia, Lisboa, Impressão da Academia das Sciências, 1783.

(22) Vicente Coelho de Seabra Silva Telles, Carta ao Ministro de Estado D. Rodrigo de Sousa Coutinho, Arquivo Histórico Ultramarino, Papéis Avulsos do Reino, 30 de Abril de 1800.

(23) F.A. Brotero, Compêndio de Botânica ou Noçoens Elementares desta Sciência, segundo os melhores escritores modernos, expostos na lingua portuguesa, Paris, 1788.

(24) Abílio Fernandes, Rev. Fac. Ciências da Universidade Coimbra, XIV (1945) pp. 51-90.

(25) Cabe notar aqui, na sequência do relato deste incidente, que na Congregação da Faculdade de Filosofia da Universidade de Coimbra, de 25 de Abril de 1801, foi apresentada nova tese, no domínio da Botânica, cujo tema mais não era que o anteriormente apresentado, com algumas modificaçðes. Intitulava-se: Seminum germinatio non est fermentatio; sed nulla germinatio absque fermentatione. Na referida Congregação se deliberou que tal tese fosse inteiramente riscada.

O novo léxico científico

\section{Caro Leitor}

O Tema deste número são os Princípios e as leis. O Princípio é o início de algo, pelo que terá de ter uma continuação. Um princípio mais tarde ou mais cedo terá também um final. Princípio, Meio e Fim são uma Trindade, o tripé do pensamento moderno.

Um princípio deve ter um objectivo isto é um fim. Um Princípio deve ter meios para se impôr. Quando acaba o Princípio? Quando Principia o Princípio? De quem foi a ideia do Princípio do Princípio?

... e se o leitor principiar a ler esta crónica sobre os princípios, desde o princípio, ...vai fatalmente chegar ao fim. O Princípio vai acabar no fim. Entre o princípio e o fim está o meio. A lei é um meio. A lei é para se cumprir. Se um cientista escreve uma lei e a lei é aprovada, desde logo toda a comunida- de científica fica obrigada à dita, até que esta seja revogada. Vejamos alguns exemplos, de principios e de leis.

Princípio da Incerteza (dito de I Heisenberg - 1927) - Teve início por volta dos anos vinte quando os Físicos se aperceberam de que algo não estava a bater totalmente certo.

Princípio da Exclusão (dito de Pauli) - Podemos situá-lo em Novembro de 1975 , se a função tiver um sinal, ou em Abril de 1974 se a função fôr de sinal contrário. (Outros autores remontam a Maio 1926, Outubro 1910 e até mais cedo... para ambos os casos).

Princípio da Combinação - (dito de Ritz - 1908) - Acordo feito pelos Políticos que se pode resumir assim. "Se votas em mim levas em troca..." (não posso continuar a escrever... bico calado!).

Princípio da Atracção Universal - (muito antigo) - Teve o seu início ainda o Homem era Macaco. Sem este princípio, não tinha havido ...principio... percebem? Princípio da Conservação da Energia (Sec. XX) - Teve a sua maior expressão nos anos setenta com a crise do Petróleo. Tudo indica que irá perdurar, sendo dificil de prever o fim deste princípio.

Princípio do Fim - Quando existe uma descontinuidade no Princípio. Neste exemplo deixamos os principios e vamos direitos ao fim, através da lei... sempre tudo legal.

Lei da acção das massas - Lei que autoriza os cidadãos a manifestar as suas opinioes, individualmente ou em associaçðes criadas para esse efeito.

Leitor - Aquele que lê as leis.

No próximo número voltamos às leis.

Florêncio Vesúvio 